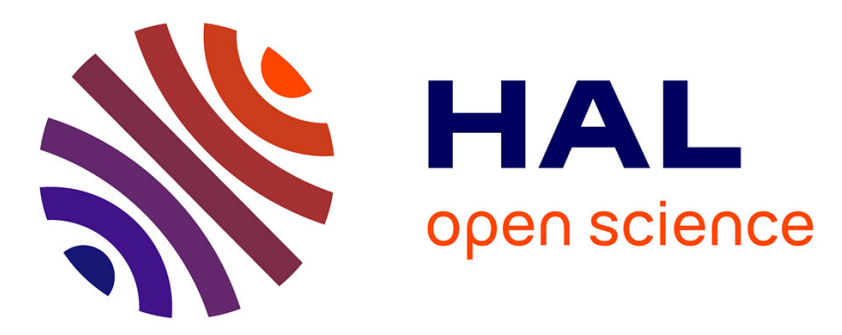

\title{
Loss of ICAM-1 signaling induces psoriasin (S100A7) and MUC1 in mammary epithelial cells
}

\author{
S. Petersson, E. Shubbar, M. Yhr, A. Kovacs, C. Enerbäck
}

\section{To cite this version:}

S. Petersson, E. Shubbar, M. Yhr, A. Kovacs, C. Enerbäck. Loss of ICAM-1 signaling induces psoriasin (S100A7) and MUC1 in mammary epithelial cells. Breast Cancer Research and Treatment, 2010, 125 (1), pp.13-25. 10.1007/s10549-010-0820-4 . hal-00554996

\section{HAL Id: hal-00554996 https://hal.science/hal-00554996}

Submitted on 12 Jan 2011

HAL is a multi-disciplinary open access archive for the deposit and dissemination of scientific research documents, whether they are published or not. The documents may come from teaching and research institutions in France or abroad, or from public or private research centers.
L'archive ouverte pluridisciplinaire HAL, est destinée au dépôt et à la diffusion de documents scientifiques de niveau recherche, publiés ou non, émanant des établissements d'enseignement et de recherche français ou étrangers, des laboratoires publics ou privés. 


\section{Loss of ICAM-1 signaling induces psoriasin (S100A7) and} MUC1 in mammary epithelial cells

Petersson $S^{1}$, Shubbar $E^{1}$, Yhr $M^{1}$, Kovacs $A^{2}$ and Enerbäck $C^{3}$

Departments of ${ }^{1}$ Clinical Genetics and ${ }^{2}$ Pathology, Sahlgrenska University Hospital, SE-413

45 Gothenburg, Sweden; ${ }^{3}$ Department of Clinical and Experimental Medicine, Division of Cell Biology and Dermatology, Linköping University, SE-581 85 Linköping, Sweden

E-mail: emman.shubbar@gu.se

E-mail: maria.yhr@ clingen.gu.se

E-mail: aniko.kovacs@vgregion.se

E-mail: charlotta.enerback@liu.se

Correspondence: Stina Petersson, Department of Clinical Genetics, Sahlgrenska University Hospital, SE-413 45 Gothenburg, Sweden

E-mail: stina.petersson@ clingen.gu.se 


\section{Abstract}

Psoriasin (S100A7), a member of the S100 gene family, is highly expressed in high-grade comedo ductal carcinoma in situ (DCIS), with a higher risk of local recurrence. Psoriasin is therefore a potential biomarker for DCIS with a poor prognosis. High-grade DCIS is characterized by a high proliferation rate and crowded cells consequently lose contact with the extracellular matrix. The aim of the present work was therefore to elucidate the involvement of adhesion signals in the regulation of psoriasin. Protein expression was evaluated by Western blotting, flow cytometry and immunohistochemistry and using breast carcinoma SAGE databases available from the CGAP website. Intercellular adhesion molecule 1 (ICAM-1) was down-regulated in MCF10A cells using short hairpin RNA. We found a significant negative correlation between the expression of ICAM-1 and psoriasin and a positive correlation between psoriasin and MUC1 in normal and DCIS SAGE libraries. In a cluster analysis of 34 adhesion molecules and 20 S100 proteins, we showed that SAGE libraries expressing the $\mathrm{S} 100$ proteins psoriasin, calgranulin-A and calgranulin-B clustered together. Interestingly, the expression of all three proteins correlated strongly to the oncogenic MUC1. We confirmed the negative correlation between ICAM-1 and psoriasin/MUC1, when normal and breast cancer cells were cultured in suspension and on collagen respectively. The down-regulation of ICAM-1 by short hairpin RNA in MCF10A cells led to the induction of psoriasin, calgranulin-A, calgranulin-B and MUC1 and we demonstrated that these upregulations were not ROS dependent. By blocking the phospholipase C (PLC)-IP3 pathway in these cells, we showed that the induction of psoriasin diminished. The results suggest that psoriasin is an intracellular calcium-dependent target of the PLC pathway. Our findings suggest that the down-regulation of ICAM-1 in mammary epithelial cells may contribute both to the high expression of psoriasin seen in some high-grade DCIS tumors and to the induction of MUC1. 
Key words: Breast cancer, ductal carcinoma in situ, psoriasin, adhesion, ICAM-1, MUC1. 


\section{Introduction}

Breast cancer is the leading cause of cancer-related death in women worldwide [1]. It has become clear that breast cancer is highly heterogeneous at both the clinical and molecular level and that each subtype of breast tumor has its own expression pattern and associated clinical outcome [2]. The specific biological mechanisms that underlie breast cancer initiation and progression remain poorly understood. Improved diagnostic tools have made it possible to detect breast cancer, such as ductal carcinoma in situ (DCIS), in its early stages, but reliable prognostic markers for this heterogeneous group of tumors are still lacking.

The S100 family is a group of calcium-binding proteins that display a change in expression in different carcinomas, including breast cancer. S100 proteins have both intracellular and extracellular functions and have been seen to play a role in various cellular processes including proliferation, differentiation and cell shape [3-5]. We and others have identified psoriasin (S100A7) as one of the few proteins that are highly and more frequently expressed in high-grade DCIS than in invasive breast carcinomas. Interestingly, the continuous expression of psoriasin in invasive breast cancer has been associated with a poor clinical outcome [6-9]. These findings indicate that psoriasin may play a role in breast cancer initiation and progression and could be a potential biomarker for DCIS with a poor prognosis. We and others have demonstrated that psoriasin expression correlates to increased survival and NFkB signaling in mammary epithelial cells $[10,11]$. Psoriasin was found to interact with JUN-activating binding protein1 (Jab1), which is involved in multiple signal transduction pathways, including the regulation of JUN/AP1 transcription factors [12]. We showed that the down-regulation of endogenous psoriasin expression in the MDA-MB-468 cell line by short hairpin RNAs increased invasion in vitro but inhibited tumor growth in vivo. In accordance with these findings, we demonstrated an up-regulation of matrix metalloproteinase 13 (MMP13) and a down-regulation of vascular endothelial growth factor (VEGF) in cells with 
reduced psoriasin levels [13]. In addition, psoriasin protein is secreted and can function as a chemotactic factor for $\mathrm{CD}^{+}$lymphocytes in the skin and, more recently, it has been implicated in the antibacterial defense mechanism of the skin [14].

We have previously demonstrated the induction of psoriasin in mammary epithelial cells by growth factor deprivation, prolonged cell confluency [8] and reactive oxygen species (ROS) [10]. In addition, the most pronounced induction of psoriasin expression was observed by the loss of attachment to the extracellular matrix (suspension culture). All of these conditions may induce the expression of psoriasin in high-grade DCIS in vivo, thus may play a role in tumorigenesis. The aim of the present work was therefore to investigate whether loss of cell adhesion signaling may contribute to the high psoriasin expression seen in some high-grade DCIS tumors.

\section{Materials and methods}

\section{Cell lines and culture condition}

The MDA-MB-468 (human breast cancer) and the MCF10A (immortalized normal breast epithelium) cell lines were obtained from American Type Culture Collection (Manassas, VA, USA) and were cultivated as previously described [15]. For suspension cultures, cells were plated into poly-2-hydroxy-ethylmethacrylate (polyHEMA) (Sigma Aldrich, Stockholm, Sweden) coated $\left(10 \mathrm{mg} / \mathrm{cm}^{2}\right.$ in $95 \%$ ethanol) Petri dishes. Effects in confluence were analyzed by maintaining the cells in confluent conditions for 5 days. To investigate the relationship between psoriasin and extracellular signaling, cells were plated on collagen-1-treated Petri dishes (Vitrogen; no. FXP-019).

To examine the effect of $\mathrm{N}$-acetylcysteine (NAC), cells were incubated with $10 \mathrm{mM}$ of the antioxidant for 1.5 hours. To investigate the role of phospholipase C (PLC), we tested U73122 (Sigma-Aldrich), a widely employed PLC inhibitor. We also tested 2-APB (Sigma-Aldrich), 
an IP3-receptor inhibitor. The influence on psoriasin protein expression was investigated 3-48 hours after treatment. The phospholipase $\mathrm{C}$ activator, m-3M3FBS (Calbiochem), was incubated for 24 hours. $\mathrm{H}_{2} \mathrm{O}_{2}$ (Sigma-Aldrich) was added to a final concentration of $0,4-1,2$ $\mathrm{mM}$ and incubated for five minutes. After the indicated time, cells were harvested and immediately frozen in liquid nitrogen or prepared for FACS analysis.

\section{Generation of short hairpin RNA clones}

For the generation of stable clones expressing short hairpin RNA (shRNA) for human ICAM1 (SuperArray, Bioscience Corporation), MCF10A cells were transfected using Lipofectamine ltx with Plus reagent (Invitrogen). Stable clones were selected for two weeks in media containing $3 \mu \mathrm{g} / \mathrm{ml}$ puromycin.

\section{Western blotting}

Western blotting was performed as previously described [15]. Western blotting analyses of cell lysate were produced with anti-psoriasin (mouse-Ab) (Imgenex, San Diego, CA, USA) and anti-calgranulin-B (mouse-Ab) (Dianova GmbH, Hamburg, Germany). Moreover, anticalgranulin-A (mouse-Ab), anti-ICAM1 (mouse-Ab), anti-MUC1 (mouse-Ab) and antiGAPDH (rabbit-Ab) (Santa Cruz Biotechnology, CA, USA) were used. Anti-phospho-PLC $\gamma 1$ (Tyr783) (rabbit-Ab) were purchased from Cell signaling Technology, USA.

\section{Flow cytometry}

Flow cytometry analyses were performed to examine the expression of ICAM-1 and MUC1 on the cell surface. Cells were trypsined and washed with $1 \times$ PBS. 1.5 to $3 \times 10^{5}$ cells were then re-suspended in $1 \times$ PBS. Antibodies were added and incubated for 30 minutes on ice. The antibodies that were used were FITC Mouse anti-human CD227 (MUC1) (BD 
Bioscience, CA, USA) at a dilution of 1:30 and FITC Mouse anti-CD54 (ICAM-1) (Diaclone, Besancon Cedex, France) at a dilution of 1:50. After another washing, cells were resuspended in $1 \times$ PBS. Flow cytometry was performed using a FACSAria (BD Immunocytometry Systems, Franklin Lakes, NJ).

\section{Tissues}

Tissue samples for immunohistochemical study were obtained from the files of the Department of Pathology at Sahlgrenska University Hospital. From a set of cases $(n=11)$ representing DCIS grade 1, 2 and 3, picked out at random, blocks of paraffin-embedded tissue samples were obtained. The tissue blocks contained tumor tissue and adjacent normal breast tissue. Histologically, the tumors showed some degree of structural heterogeneity. The individual tumors contained a single or several components of papillar, cribriform, solid and comedo-type structures. See Online Resource 1 for the original data.

\section{Immunohistochemistry}

A monoclonal antibody to psoriasin, commercially available from Imgenex (Imgenex, San Diego, CA, USA), a monoclonal anti-MUC1 antibody and anti-ICAM-1 antibody (Santa Cruz Biotechnology) were used. The psoriasin antibody was used at a dilution of 1:200, the MUC1 antibody at a dilution of 1:500 and ICAM-1 at a dilution of 1:400 (25 $\mathrm{min}$ at room temperature). Antigen-antibody complexes were visualized with an $\mathrm{ABC}$ detection system using diaminobenzidine (DAB) as the chromogen. The study was performed under conditions approved by the Ethics Committee at the University of Gothenburg. All slides were evaluated by an experienced breast pathologist (AK). 


\section{SAGE Genie informatics}

SAGE Genie is a website for the analysis and presentation of SAGE data (http://cgap.nci.nih.gov/SAGE) created by the Cancer Genome Anatomy Project (CGAP) SAGE project. These informatics provide a quantitative view of the transcription levels of selected genes in many different tissues [16]. The tumors used for SAGE analysis were six normal mammary tissues (N1-N6), five high-grade comedo DCIS (D1, D3, D4, D5 and D6), three intermediate-grade tumors with no necrosis (D2, D7 and D8), nine invasive tissues and three metastatic tissues. The SAGE libraries analyzed in this paper have been previously reported $[17,18]$.

\section{Hierarchical clustering}

Unsupervised hierarchical clustering was applied to data using the HCE 3.5 clustering program with the aim of identifying subgroups of tumors with similar expression patterns. Kmean clustering available in the HCE 3.5 clustering program was also applied. The output of a cluster analysis is a dendrogram, which illustrates the grouping.

\section{Nitro Blue Tetrazolium (NBT) assay for detection of ROS}

The NBT assay was performed as described previously [19]. Briefly, NBT (Sigma) was added at a final concentration of $1 \mathrm{mg} / \mathrm{ml}$ and the incubation were carried out at $37 \mathrm{C}^{\circ}$ for $3 \mathrm{~h}$. Intracellular blue formazan particles were dissolved in $960 \mu \mathrm{l}$ of $2 \mathrm{M} \mathrm{KOH}$ (Sigma Aldrich) and $1120 \mu \mathrm{l}$ of DMSO and the OD was then measured at $630 \mathrm{~nm}$ using a multi-well plate reader. 


\section{Statistical analysis}

Correlation analysis was assessed by Spearman's rank correlation test (r). To illustrate the relationship between the expressions of two genes, a scatter plot was applied using SPSS 15.0.

\section{Results}

\section{Synthetic RGD-containing peptides do not induce psoriasin}

Integrin receptors are the main mediators of cell adhesion to the extracellular matrix (ECM). They bind to their ligands by interacting with short amino acid sequences, such as the RGD sequence (Arg-Gly-Asp). This sequence is recognized by many, but not all of the known integrins. This sequence can be blocked by short synthetic peptides containing the RGD sequence. Using this RGD-competitive ligand inhibitor for integrin binding, no induction of psoriasin was observed (data not shown). Integrins recognizing this sequence do not therefore appear to influence the regulation of psoriasin expression by ECM contact.

\section{ICAM-1 is negatively correlated to psoriasin expression}

We have previously shown that IFN- $\gamma$ down-regulated psoriasin expression induced by suspension culture in normal breast epithelial cells [15]. This finding led to the hypothesis that IFN- $\gamma$ may interfere with the psoriasin-regulating adhesion signaling that is lost in suspension cultures.

IFN- $\gamma$ is a multifunctional cytokine that activates the transcription of many genes. Using microarray analysis, de Veer et al. identified > 300 interferon-stimulated genes, ISG [20]. Using the ISG database available on their website, 13 adhesion-related molecules stimulated by IFN- $\gamma$ were selected (Table 1). Utilizing the SAGE database available from the CGAP website, the expression level of these IFN- $\gamma$-stimulated adhesion molecules and psoriasin 
were analyzed in normal breast tissue and DCIS tumors. Our hypothesis was to find a negative correlation between adhesion molecules and psoriasin, therefore we used one-tailed t-test. Of the 13 candidates studied, ICAM-1 and thrombospondin 1 exhibited a significant negative correlation with psoriasin expression in normal and DCIS specimens (Table 1).

\section{MUC1 is positively correlated to the expression of psoriasin, calgranulin-A and calgranulin-B}

To further evaluate the role of adhesion molecules potentially involved in the regulation of psoriasin expression, we analyzed 34 adhesion molecules and 20 S100 proteins in normal and DCIS SAGE libraries. A hierarchical cluster algorithm was used to group together samples with similar gene expression characteristics. The three DCIS specimens, D1, D4 and D8, clustered together. These tumors are characterized by the high expression of psoriasin (S100A7), calgranulin-A (S100A8) and calgranulin-B (S100A9) (Fig 1). These results were also confirmed with $\mathrm{k}$-mean clustering $(\mathrm{k}=2)$. We analyzed the correlation between these three S100 proteins and the expression of the 34 adhesion proteins (Table 2). Interestingly, the expression of the tumor-associated MUC1, which is a ligand for intracellular adhesion molecule 1 (ICAM-1), demonstrated a significant positive correlation to the expression of all three $\mathrm{S} 100$ proteins $(\mathrm{p}<0.05)$.

The expression level of psoriasin, ICAM-1, thrombospondin 1 and MUC1 is illustrated in figure 2. Specifically, psoriasin, as well as MUC1, were highly up-regulated in DCIS compared with normal breast tissue, while ICAM-1 was down-regulated. Thrombospondin 1 showed low expression levels.

Next, we assessed the relative gene ratios of psoriasin, MUC1 and ICAM-1 in each individual normal and DCIS library. Although based on few observations, psoriasin and MUC1 are 
positively correlated to each other (Fig 3a) and both proteins are negatively correlated to ICAM-1 (Fig 3b and c).

ICAM-1 is negatively correlated to psoriasin/MUC1 in suspension culture and culture on collagen

We examined the expression of ICAM-1/MUC1/psoriasin in suspension cultures of the immortalized normal epithelial MCF10A. As shown in figure 4, psoriasin and MUC1 are upregulated when cells are cultured in suspension, whereas ICAM-1 is down-regulated. This finding suggests that the down-regulation of ICAM-1 in suspension culture may contribute to the strong induction of psoriasin and also MUC1.

To further investigate the relationship between psoriasin and extracellular signaling, we cultured MDA-MB-468 cells on collagen-treated Petri dishes (Figure 5). After three passages, ICAM-1 expression was induced, whereas psoriasin and MUC1 expression was almost abolished. The membrane-bound protein expression was analyzed by FACS analysis. We confirmed that cells cultured on collagen expressed higher levels of ICAM-1, whereas MUC1 expression was down-regulated.

Down-regulation of ICAM-1 expression by shRNA led to the induction of psoriasin, calgranulin-A, calgranulin-B and MUC1

To investigate the direct effect of ICAM-1 gene silencing, we transfected MCF10A cells with shRNA targeting ICAM-1 mRNA. Each of three independent transfections generated three stably transfected knockdown clones and a control clone. Figure 6 show that shRNA used against ICAM-1 expression gave rise to induced psoriasin and MUC1 expression. Moreover, the down-regulation of ICAM-1 also led to the over-expression of calgranulin-A and calgranulin-B. Using flow cytometry, we confirmed the significant down-regulation of cell 
surface ICAM-1 and we also demonstrated a significant up-regulation of cell surface MUC1. To confirm that these results were not only restricted to MCF10A cells, HEKn (primary human keratinocyte) transfected with small interfering RNA targeting ICAM-1 mRNA was demonstrated to strongly up-regulate psoriasin (data not shown).

\section{The up-regulation of psoriasin by ICAM-1 shRNA is mediated by the phospholipase C (PLC)-IP3 pathway}

The binding of MUC1 to ICAM-1 was found to induce intracellular calcium signaling mediated by the phospholipase C (PLC)-IP3 pathway [21]. To evaluate whether the induction of psoriasin is mediated through activation of the PLC pathway, cells were treated with two different inhibitors; the IP3 inhibitor 2-APB and the PLC inhibitor U73122. As shown in figure $7 \mathrm{a}$ and $7 \mathrm{~b}$, the expression of psoriasin in the MCF10A ICAM-1-shRNA cells decreased after treatment with 2-APB or U73122. MUC1 was also decreased after treatment with these inhibitors (Fig 8). Moreover, we also demonstrated that psoriasin was induced by the PLC activator, m-3M3FBS, in MCF10A cells (Fig 9). Functionality of the PLC activator, m3M3FBS, and the inhibitor U73122 was demonstrated by phosphorylation of PLC $\gamma 1$, which confirms an active signaling pathway (Fig 10).

We have previously demonstrated that psoriasin is induced by ROS and down-regulated by Bcl-2 and other antioxidants like NAC [10]. We therefore used NAC in MCF10A ICAM-1shRNA cells and demonstrated a prominent expression of psoriasin after the treatment (Fig 11a). We also applied NBT assay to measure ROS production in MCF10A ICAM-1-shRNA cells with upregulated psoriasin, compared to control-shRNA cells. We found no difference in intracellular ROS levels (Fig 11b). Therefore, ROS cannot explain the upregulation of psoriasin by ICAM-1 downregulation. 
We have previously shown that psoriasin is induced by confluent conditions [8]. Moreover, psoriasin is highly expressed in the MDA-MB-468 breast cancer cell line. To investigate the involvement of the PLC pathway in the induction of psoriasin in these conditions, we treated confluent MCF10A cells and MDA-MB-468 cells with the IP3-receptor inhibitor 2-APB and the PLC inhibitor U73122. Interestingly, no decrease in psoriasin expression was seen after treatment (Fig 12).

\section{Psoriasin over-expression does not affect ICAM-1 or MUC1}

We used MCF10A cells with a stable retroviral over-expression of psoriasin to detect changes in ICAM-1 and MUC1 expression by flow cytometry (Fig 13). A significant yet minor change in ICAM-1 expression was identified. We also investigated the effect of extracellularly administered psoriasin. There was no influence of ICAM-1 or MUC1 expression (data not shown). We therefore found no evidence of reciprocal negative regulation between psoriasin and ICAM-1.

\section{Heterogenous expression of psoriasin, ICAM-1 and MUC1 using immunohistochemistry}

The expression of psoriasin, ICAM-1 and MUC1 in a set of DCIS cases showed a marked degree of heterogeneity, both between and within samples (see Online Resource 1). In normal mammary epithelial components, psoriasin was expressed in only one of the cases. In DCIS cells, on the other hand, psoriasin was strongly upregulated but commonly only in a fraction of the cells, often surrounded by cells with no or weak psoriasin expression. However, a few DCIS samples altogether lacked psoriasin expression. MUC1 was weakly to moderately expressed in normal epithelial cells, and strongly in all DCIS samples except one; this sample also lacking psoriasin expression. Also ICAM-1 showed a heterogenous expression, both in normal cells and in the DCIS components. Thus, both normal mammary epithelial cells and 
DCIS cells showed weak or even negative, to moderate staining. Because of this complex picture, a grading of expression of the different proteins in individual tumors was not found meaningful. Interestingly, in apocrine metaplasia representing differentiated normal epithelial cells, ICAM-1 was downregulated whereas psoriasin was upregulated. Endothelial cells and inflammatory cells stained strongly for ICAM-1 both in the tumor stroma and in the stroma of normal parts of the samples. The staining was strong without the variation in intensity observed in mammary epithelial cells.

\section{Discussion}

Adhesion plays a central role in cell survival. Cell-cell interaction and the anchorage of cells to components of the extracellular matrix $(\mathrm{ECM})$ are mediated primarily by integrins and other adhesion molecules [22]. During the initiation of breast cancer, epithelial cells hyperproliferate, which leads to changes in adhesion to the basal membrane. In high-grade DCIS, which is an early form of breast cancer, psoriasin is one of the few proteins that are very highly expressed. We have observed that psoriasin is induced in vitro in suspension cultures of normal mammary epithelial cells (MCF10A). IFN- $\gamma$ treatment specifically down-regulate psoriasin expression in suspension cultures [15]. Among the adhesion molecules implicated in cell-cell interactions, CD54 or ICAM-1 have previously been identified to be up-regulated in response to IFN- $\gamma$ at the transcriptional level [22]. ICAM-1 is an important member of the immunoglobulin superfamily (IgSF) of proteins that is essentially involved in the recruitment and trafficking of leukocytes [23]. In contrast to the constitutive expression of ICAM-1 in the endothelium, human epithelial cells normally have a low expression. In the normal and DCIS SAGE libraries, we confirmed a significant negative correlation between the expression of psoriasin and ICAM-1 levels. To confirm a connection between psoriasin induction and the loss of ICAM-1 expression in normal breast epithelial cells, we demonstrated that ICAM-1 
was in fact down-regulated in suspension, making this protein an interesting candidate for further analysis.

We performed a cluster analysis of 34 adhesion molecules and 20 S100 proteins and report a strong association between the expression of psoriasin, calgranulin-A and calgranulin-B. Like psoriasin, we have demonstrated that calgranulin-A and calgranulin-B are induced by ROS, confluence and suspension culture, which supports the assumption that they share common signaling pathways in breast cancer. Their co-expression may suggest that the combined upregulation of these three proteins reflects a group of breast cancer with a poor prognosis. In line with this, the cluster analysis revealed that all three proteins correlated strongly to the oncogenic MUC1. MUC1, which is a transmembrane glycoprotein, is an established tumor marker in breast cancer and is implicated in metastatic spread. In addition to psoriasin, calgranulin-A and calgranulin-B, MUC1 was also induced in suspension cultures of normal breast epithelial cells.

When looking into the relative gene ratios of psoriasin, ICAM-1 and MUC1 in each individual normal and DCIS library in our study, we found a significant negative correlation between ICAM-1 and psoriasin and a corresponding positive correlation between MUC1 and psoriasin. We confirmed the negative correlation between ICAM-1 and psoriasin/MUC1, when cells were cultured on collagen.

The direct regulatory effect was suggested by the use of shRNA targeting ICAM-1 mRNA in MCF10A cells. The down-regulation of ICAM-1 expression by shRNA thus led to the induction of psoriasin, calgranulin-A, calgranulin-B and MUC1.

Next, we focused on the mechanism for the up-regulation of psoriasin in the MCF10A cells with reduced expression of ICAM-1. We still detected an expression of psoriasin after treatment with the antioxidant NAC. Moreover, there was no increase in intracellular ROS in cells with reduced expression of ICAM-1. These findings suggest that signals other than ROS 
production contribute to the regulation of psoriasin in this context. ICAM-1 is the only known ligand of the MUC1 extracellular domain [24]. Rahn et al. showed that MUC1 initiates a calcium-based signal mediated by the phospholipase C (PLC)-IP3 pathway, involved in intracellular calcium signaling [21]. Using the inhibitors U73122 and 2-APB for the PLC pathway, the induction of psoriasin and MUC1 in these cells were reduced. Moreover, the PLC activator m-3M3FBS was shown to increase the expression of psoriasin in normal mammary epithelial cells. These finding supports the hypothesis that psoriasin is an intracellular calcium-dependent target of the PLC pathway.

The immunohistochemical analysis from a set of DCIS cases emphasized the high degree of heterogeneity within and between samples. The lack of complete concordance between the results from the analysis of normal and DCIS SAGE libraries compared to the immunohistochemistry may be explained by the fact that SAGE libraries are prepared from fresh tissue and represent mRNA expression, whereas protein expression are assessed in immunohistochemistry. Moreover, the normal mammary epithelial cells within and close to a DCIS lesion may not be regarded as completely normal, since it is known that there is a dramatic change in gene expression in stroma cells surrounding the malignant epithelial cells [25].

MUC1 is implicated in many physiological processes such as adhesion, development and differentiation. In addition, MUC1 is frequently over-expressed in many cancers including breast cancer with a predominantly cytoplasmic expression [26]. The over-expression of MUC1 is associated with a poorer prognosis and shorter survival in many cancers, including breast cancer. The co-expression of psoriasin and MUC1 may contribute to the poor clinical outcome characteristic for tumors over-expressing psoriasin. Interestingly, both MUC1 and psoriasin correlate with increased survival in response to oxidative stress [10, 27]. Moreover, both proteins have been shown to be regulated by the NFkB pathway [10, 28]. MUC1 affect 
cancer cell migration by increasing E-cadherin/beta-catenin complex formation [29] and the down-regulation of psoriasin has also been linked to increased beta-catenin signalling [30]. We now report their co-expression in response to ICAM-1 down-regulation and the positive correlation between their expressions in breast SAGE libraries.

In conclusion, we have presented data suggesting that the loss of ICAM-1 expression on normal mammary epithelial cells may contribute to the high expression of psoriasin in highgrade DCIS. The upregulation of psoriasin by ICAM1 shRNA was mediated by the phopholipase C (PLC)-IP3 pathway. Furthermore, the downregulation of ICAM-1 led to the induction of calgranulin-A, calgranulin-B and MUC1.

\section{Acknowledgments}

We thank Dr Kornelia Polyak at DFCI, Boston, MA, for generous help and valuable suggestions. We thank Katarina Junevik (Sahlgrenska University Hospital, Gothenburg) for her help with flow cytometry analysis. We thank Maria Nethander at the Genomics Core Facility (Gothenburg) for the help with hierarchical clustering analysis. This work was supported by grants from the Swedish Cancer Society, the Swedish Psoriasis Association, the Assar Gabrielsson Foundation, the Welander Foundation and the Tore Nilsson Foundation.

\section{References}

1. Kamangar F, Dores GM, Anderson WF (2006) Patterns of cancer incidence, mortality, and prevalence across five continents: defining priorities to reduce cancer disparities in different geographic regions of the world. J Clin Oncol 24:2137-2150.

2. Polyak K (2007) Breast cancer: origins and evolution. J Clin Invest 117:3155-3163.

3. Martinsson H, Yhr M, Enerback C (2005) Expression patterns of S100A7 (psoriasin) and S100A9 (calgranulin-B) in keratinocyte differentiation. Exp Dermatol 14:161168.

4. Santamaria-Kisiel L, Rintala-Dempsey AC, Shaw GS (2006) Calcium-dependent and independent interactions of the S100 protein family. The Biochemical journal 396:201-214. 
5. Donato R (2001) S100: a multigenic family of calcium-modulated proteins of the EFhand type with intracellular and extracellular functional roles. The international journal of biochemistry \& cell biology 33:637-668.

6. Leygue E, Snell L, Hiller T, Dotzlaw H, Hole K, Murphy LC, Watson PH (1996) Differential expression of psoriasin messenger RNA between in situ and invasive human breast carcinoma. Cancer Res 56:4606-4609.

7. Emberley ED, Alowami S, Snell L, Murphy LC, Watson PH (2004) S100A7 (psoriasin) expression is associated with aggressive features and alteration of Jab1 in ductal carcinoma in situ of the breast. Breast Cancer Res 6:R308-315.

8. Enerback C, Porter DA, Seth P, Sgroi D, Gaudet J, Weremowicz S, Morton CC, Schnitt S, Pitts RL, Stampl J, Barnhart K, Polyak K (2002) Psoriasin expression in mammary epithelial cells in vitro and in vivo. Cancer Res 62:43-47.

9. Al-Haddad S, Zhang Z, Leygue E, Snell L, Huang A, Niu Y, Hiller-Hitchcock T, Hole K, Murphy LC, Watson PH (1999) Psoriasin (S100A7) expression and invasive breast cancer. The American journal of pathology 155:2057-2066.

10. Carlsson H, Yhr M, Petersson S, Collins N, Polyak K, Enerback C (2005) Psoriasin (S100A7) and calgranulin-B (S100A9) induction is dependent on reactive oxygen species and is downregulated by Bcl-2 and antioxidants. Cancer Biol Ther 4:998-1005.

11. Emberley ED, Niu Y, Curtis L, Troup S, Mandal SK, Myers JN, Gibson SB, Murphy LC, Watson PH (2005) The S100A7-c-Jun activation domain binding protein 1 pathway enhances prosurvival pathways in breast cancer. Cancer Res 65:5696-5702.

12. Emberley ED, Niu Y, Leygue E, Tomes L, Gietz RD, Murphy LC, Watson PH (2003) Psoriasin interacts with Jab1 and influences breast cancer progression. Cancer Res 63:1954-1961.

13. Krop I, Marz A, Carlsson H, Li X, Bloushtain-Qimron N, Hu M, Gelman R, Sabel MS, Schnitt S, Ramaswamy S, Kleer CG, Enerback C, Polyak K (2005) A putative role for psoriasin in breast tumor progression. Cancer Res 65:11326-11334.

14. Glaser R, Harder J, Lange H, Bartels J, Christophers E, Schroder JM (2005) Antimicrobial psoriasin (S100A7) protects human skin from Escherichia coli infection. Nat Immunol 6:57-64.

15. Petersson S, Bylander A, Yhr M, Enerback C (2007) S100A7 (Psoriasin), highly expressed in ductal carcinoma in situ (DCIS), is regulated by IFN-gamma in mammary epithelial cells. BMC cancer 7:205.

16. Boon K, Osorio EC, Greenhut SF, Schaefer CF, Shoemaker J, Polyak K, Morin PJ, Buetow KH, Strausberg RL, De Souza SJ, Riggins GJ (2002) An anatomy of normal and malignant gene expression. Proc Natl Acad Sci U S A 99:11287-11292.

17. Porter DA, Krop IE, Nasser S, Sgroi D, Kaelin CM, Marks JR, Riggins G, Polyak K (2001) A SAGE (serial analysis of gene expression) view of breast tumor progression. Cancer Res 61:5697-5702.

18. Porter D, Lahti-Domenici J, Keshaviah A, Bae YK, Argani P, Marks J, Richardson A, Cooper A, Strausberg R, Riggins GJ, Schnitt S, Gabrielson E, Gelman R, Polyak K (2003) Molecular markers in ductal carcinoma in situ of the breast. Mol Cancer Res $1: 362-375$.

19. Wadsworth TL, Bishop JA, Pappu AS, Woltjer RL, Quinn JF (2008) Evaluation of coenzyme Q as an antioxidant strategy for Alzheimer's disease. J Alzheimers Dis $14: 225-234$.

20. de Veer MJ, Holko M, Frevel M, Walker E, Der S, Paranjape JM, Silverman RH, Williams BR (2001) Functional classification of interferon-stimulated genes identified using microarrays. Journal of leukocyte biology 69:912-920. 
21. Rahn JJ, Shen Q, Mah BK, Hugh JC (2004) MUC1 initiates a calcium signal after ligation by intercellular adhesion molecule-1. The Journal of biological chemistry 279:29386-29390.

22. Hou J, Baichwal V, Cao Z (1994) Regulatory elements and transcription factors controlling basal and cytokine-induced expression of the gene encoding intercellular adhesion molecule 1. Proc Natl Acad Sci U S A 91:11641-11645.

23. Reiss Y, Hoch G, Deutsch U, Engelhardt B (1998) T cell interaction with ICAM-1deficient endothelium in vitro: essential role for ICAM-1 and ICAM-2 in transendothelial migration of T cells. European journal of immunology 28:3086-3099.

24. Hayashi $\mathrm{T}$, Takahashi $\mathrm{T}$, Motoya S, Ishida $\mathrm{T}$, Itoh $\mathrm{F}$, Adachi M, Hinoda Y, Imai $\mathrm{K}$ (2001) MUC1 mucin core protein binds to the domain 1 of ICAM-1. Digestion 63 Suppl 1:87-92.

25. Allinen M, Beroukhim R, Cai L, Brennan C, Lahti-Domenici J, Huang H, Porter D, Hu M, Chin L, Richardson A, Schnitt S, Sellers WR, Polyak K (2004) Molecular characterization of the tumor microenvironment in breast cancer. Cancer cell 6:17-32.

26. Rahn JJ, Dabbagh L, Pasdar M, Hugh JC (2001) The importance of MUC1 cellular localization in patients with breast carcinoma: an immunohistologic study of 71 patients and review of the literature. Cancer 91:1973-1982.

27. Yin L, Li Y, Ren J, Kuwahara H, Kufe D (2003) Human MUC1 carcinoma antigen regulates intracellular oxidant levels and the apoptotic response to oxidative stress. The Journal of biological chemistry 278:35458-35464.

28. Thompson EJ, Shanmugam K, Hattrup CL, Kotlarczyk KL, Gutierrez A, Bradley JM, Mukherjee P, Gendler SJ (2006) Tyrosines in the MUC1 cytoplasmic tail modulate transcription via the extracellular signal-regulated kinase $1 / 2$ and nuclear factorkappaB pathways. Mol Cancer Res 4:489-497.

29. Yuan Z, Wong S, Borrelli A, Chung MA (2007) Down-regulation of MUC1 in cancer cells inhibits cell migration by promoting E-cadherin/catenin complex formation. Biochem Biophys Res Commun 362:740-746.

30. Zhou G, Xie TX, Zhao M, Jasser SA, Younes MN, Sano D, Lin J, Kupferman ME, Santillan AA, Patel V, Gutkind JS, Ei-Naggar AK, Emberley ED, Watson PH, Matsuzawa SI, Reed JC, Myers JN (2008) Reciprocal negative regulation between S100A7/psoriasin and beta-catenin signaling plays an important role in tumor progression of squamous cell carcinoma of oral cavity. Oncogene 27:3527-3538.

31. SAGE genie informatics [http://cgap.nci.nih.gov/SAGE] 


\section{Figure legends}

Fig 1 Hierarchical cluster analysis of adhesion-related molecules and S100 proteins in breast epithelial SAGE libraries. Using SAGE Genie, the quantitative transcription level of S100 proteins and adhesion molecules was viewed in breast epithelial SAGE libraries. The expression profiles of normal epithelium and DCIS are compared using cluster analysis. a, Dendrogram image demonstrates the degree of relatedness between the tissue samples. Each sample is represented by a single branch at the bottom of the dendrogram. Samples displaying similar patterns of expression are grouped together on closely connected branches of the dendrogram. b, Image demonstrates the level of gene expression and is represented by the intensity of green color (low expression), black color (medium expression) and red color (high expression). Each column represents a tissue sample and each row represents a gene. The three DCIS libraries, D1, D4 and D8, clustered together. These tumors are characterized by the high concomitant expression of psoriasin (S100A7), calgranulin-A (S100A8), calgranulin-B (S100A9) and MUC1.

Fig 2 Mean value of SAGE tags in normal, DCIS, invasive and metastatic breast tissues. Using SAGE Genie, the quantitative transcription level of ICAM-1, MUC1, thrombospondin 1 and psoriasin was viewed in breast epithelial SAGE libraries. An average value plus standard error of the obtained SAGE tags was calculated for the different stages (indicated in the bar). The values indicated represent SAGE tags per 200,000 transcripts. ICAM-1 expressed in normal tissue is down-regulated in DCIS, invasive and metastatic tumors, whereas psoriasin and MUC1 expression is specifically highly expressed in some DCIS tumors. Thrombospondin 1 showed low expression with minor changes between the different stages. Using two-tailed t-test, a significant difference is shown for ICAM-1 between the normal and invasive SAGE libraries $(\mathrm{p}<0.05)$. 
Fig 3 Illustration of psoriasin, ICAM-1 and MUC1 expression in individual normal and DCIS SAGE libraries. Using SAGE Genie, the quantitative transcription level of psoriasin, ICAM-1 and MUC1 of each individual normal and DCIS library was assessed. The scatter plot image demonstrates a positive correlation between psoriasin and MUC1 $(\mathrm{p}=0.02$, spearman rank correlation $r=0,613$, two-tailed) (a) and a negative correlation between psoriasin and ICAM-1 ( $p=0.048$, spearman rank correlation $r=-0,463$, one-tailed) (b). MUC1 is negatively correlated with ICAM-1 ( $\mathrm{p}=0.042$, spearman rank correlation, $r=-0,549$, two-tailed) $(\mathbf{c})$. The indicated values represent SAGE tags per 200,000 transcripts.

Fig 4 ICAM-1 is reduced, whereas MUC1 is induced, in suspension cultures of normal mammary epithelial cells. a, Western blot analysis of ICAM-1 and psoriasin in normal epithelial cells (MCF10A) cultured in suspension for 48 hours. ICAM-1 expression is suppressed, whereas psoriasin is induced. Equal amounts of protein lysate were loaded on the gels. GAPDH assesses equal loading. b, Using flow cytometry, an up-regulation of MUC1 was demonstrated (* $\mathrm{p}<0.05$, two-tailed t-test) after 72 hours in suspension. The median values obtained in control cells were designed as 1 and suspension cells were normalized to this from the same run. The data are presented as the means and ranges of six different experiments.

Fig 5 Type 1 collagen reduces psoriasin and MUC1 expression and induces ICAM-1 expression in MDA-MB-468 cells. a, Using Western blot analysis, endogenous psoriasin and MUC1 in MDA-MB-468 cells are reduced when cells are cultured on collagen-1-treated Petri dishes, whereas ICAM-1 is induced. $100 \mu \mathrm{g}$ of protein lysate were loaded on the gel. GAPDH assesses equal loading. b, Flow cytometry analysis confirms the up-regulation of ICAM-1 and 
down-regulation of MUC1 on collagen-cultured cells (* $\mathrm{p}<0.05$, one-tailed t-test). The median values obtained in control cells were designed as 1 and collagen-cultured cells were normalized to this from the same run. The data are presented as the means and ranges of three independent experiments.

Fig 6 shRNA-mediated knockdown of ICAM-1 induces psoriasin, calgranulin-A, calgranulinB and MUC1. a, The silencing of ICAM-1 with shRNA led to the induction of psoriasin, calgranulin-A and calgranulin-B in normal epithelial cells (MCF10A). $100 \mu \mathrm{g}$ of protein lysate were loaded on the gel. GAPDH assesses equal loading. MDA-MB-468 serves as a positive control. b, Using flow cytometry, the down-regulation of ICAM-1 and an upregulation of MUC1 was demonstrated ( $* \mathrm{p}<0.05$, one-tailed t-test). The median values obtained in C-shRNA cells were designed as 1 and ICAM-1-shRNA 2 cells were normalized to this from the same run. The data are presented as the means and ranges of three different runs.

Fig 7 Psoriasin induction, by ICAM-1 silencing, is suppressed by phospholipase C (PLC)-IP3 inhibitors. The inhibition of phospholipase C (PLC)-IP3 using 2-APB (a) and U73122 (b) led to reduced psoriasin expression in MCF10A ICAM-1-shRNA cells. Psoriasin decreased after 2-APB treatment $(100 \mu \mathrm{M})$. Treatment with the PLC inhibitor U73122 $(10 \mu \mathrm{M})$ for 3, 6 and 12 hours reduced psoriasin expression. Equal amounts of protein lysate were loaded on the gels. GAPDH assesses equal loading. Psoriasin expression was quantified by the AlphaEaseFC ${ }^{\mathrm{TM}}$ software. Quantified results were adjusted with their own GAPDH level and control cells were designed as 1 and treated cells were normalized to this. 
Fig 8 MUC1 induction, by ICAM-1 silencing, is suppressed by phospholipase C (PLC)-IP3

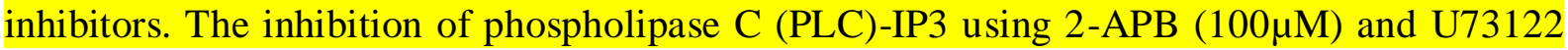
$(10 \mu \mathrm{M})$ led to reduced MUC1 expression in MCF10A ICAM-1-shRNA cells. Equal amounts of protein lysate were loaded on the gel. GAPDH assesses equal loading.

Fig 9 Phospholipase $\mathrm{C}$ activation induces psoriasin in normal mammary epithelial cells. Treatment with the phospholipase $\mathrm{C}$ activator, $\mathrm{m}-3 \mathrm{M} 3 \mathrm{FBS}$, induced psoriasin expression in the MCF10A cell line (24 hours). Control cells were incubated with dimethylsulfoxide (DMSO) alone (concentration equivalent to that used for $100 \mu \mathrm{M}$ m-3M3FBS). $90 \mu \mathrm{g}$ of protein lysate were loaded on the gel. GAPDH assesses equal loading. Psoriasin expression was quantified by the AlphaEaseFC ${ }^{\mathrm{TM}}$ software. Quantified results were adjusted with their own GAPDH level and control cells were designed as 1 and treated cells were normalized to this.

Fig 10 Functionality of the phospholipase C activator, m-3M3FBS, and the inhibitor U73122. a, Treatment with $100 \mu \mathrm{M}$ of m-3M3FBS stimulated the phosphorylation of PLC $\gamma 1$ (pPLC $\gamma 1$ ) in MCF10A, which confirms an active signaling pathway. Control cells were incubated with dimethylsulfoxide (DMSO) alone (concentration equivalent to that used for $100 \mu \mathrm{M} \mathrm{m}$ 3M3FBS). b, Phosphorylation of PLC $\gamma 1$ in MCF10A cells, using $\mathrm{H}_{2} \mathrm{O}_{2}$, is reduced using the PLC inhibitor U73122. MCF10A cells were treated with U73122. After three hours, cells were incubated with $0.4-1.2 \mathrm{mM} \mathrm{H}_{2} \mathrm{O}_{2}$ for five minutes. Control cells were incubated with ethanol alone (concentration equivalent to that used for $1.2 \mathrm{mM} \mathrm{U73122).} \mathrm{Quantified} \mathrm{results}$ were adjusted with their own GAPDH level and control cells were designed as 1 and treated cells were normalized to this. Equal amounts of protein lysate were loaded on the gels. GAPDH assesses equal loading. 
Fig 11 Induction of psoriasin, by ICAM-1 silencing, is not explained by ROS production. a, Cells were incubated with $10 \mathrm{mM}$ of the antioxidant NAC for 1.5 hours. There was still a prominent expression of psoriasin after the treatments. $60 \mu \mathrm{g}$ of protein lysate were loaded on the gel. GAPDH assesses equal loading. b, We applied NBT assay to measure ROS production in MCF10A ICAM-1-shRNA cells and in MCF10A control-shRNA cells. We found no difference in intracellular ROS levels $(\mathrm{p}=0.27$, one-tailed $t$-test). The values are an average of two independent experiments performed in triplicates.

Fig 12 Endogenous psoriasin and psoriasin induced by confluence is not suppressed by phospholipase C (PLC)-IP3 inhibitors. Endogenous psoriasin in the MDA-MB-468 cell line (a) and psoriasin induced by confluence (5 days) in the MCF10A cell line (b) is not downregulated by the 2-APB $(100 \mu \mathrm{M})$ or $\mathrm{U} 73122(10 \mu \mathrm{M})$ inhibitors. Equal amounts of protein lysate were loaded on the gels. MDA-MB-468 serves as a positive control. GAPDH assesses equal loading. Psoriasin expression was quantified by the AlphaEaseFC ${ }^{\mathrm{TM}}$ software. Quantified results were adjusted with their own GAPDH level and control cells were designed as 1 and treated cells were normalized to this.

Fig 13 Retroviral over-expression of psoriasin does not change ICAM-1 and MUC1 expression. MCF10A cells over-expressing psoriasin displayed no major change in ICAM-1 and MUC1 expression level using flow cytometry ( $* \mathrm{p}<0.05$, one-tailed t-test). Median values obtained in vector-transfected cells were designed as 1 and psoriasin-transfected cells were normalized to this from the same run. The data are presented as the means and ranges of three different runs. 


\section{Tables}

Table 1. Correlation of adhesion-related molecules stimulated by IFN-gamma with psoriasin expression in breast epithelial SAGE libraries.

\begin{tabular}{|c|c|c|c|c|c|}
\hline Gene & Unigene & Description & Spearman correlation & Sig. (1-tailed) & $\mathrm{N}$ \\
\hline ALCAM & Hs.591293 & Activated leukocyte cell adhesion molecule & $-0,198$ & 0,248 & 14 \\
\hline ARHC & Hs.502659 & Ras homolog gene family, member $\mathrm{C}$ & 0,218 & & 14 \\
\hline CDH5 & Hs.76206 & Cadherin 5 & 0,203 & & 14 \\
\hline CD47 & Hs.446414 & CD47 molecule & $-0,194$ & 0,253 & 14 \\
\hline CLDN5 & Hs.505337 & Claudin 5 & $-0,037$ & 0,450 & 14 \\
\hline DSG1 & Hs.2633 & Desmoglein 1 & $-0,192$ & 0,255 & 14 \\
\hline ICAM-1 & Hs.643447 & Intercellular adhesion molecule 1 & $-0,463$ & ${ }^{*} 0,048$ & 14 \\
\hline IFITM1 & Hs. 458414 & Interferon induced transmembrane protein & 0,014 & & 14 \\
\hline ITGA2 & Hs.482077 & Integrin alpha 2 & - & - & 14 \\
\hline KAL1 & Hs.521869 & Kallmann syndrome 1 sequence & 0,285 & & 14 \\
\hline SELL & Hs.82848 & Selectin L & 0,191 & & 14 \\
\hline THBD & Hs.2030 & Thrombomodulin & $-0,348$ & 0,111 & 14 \\
\hline THBS1 & Hs.164226 & Thrombospondin 1 & $-0,709$ & ${ }^{* *} 0,002$ & 14 \\
\hline
\end{tabular}

$\mathrm{N}$, number of libraries

${ }^{*}$ Correlation is significant at the 0,05 level

${ }^{* *}$ Correlation is significant at the 0,01 level

Table 2. Adhesion-related molecules correlating with psoriasin, calgranulin-A or calgranulin-B expression in breast epithelial SAGE libraries.

\begin{tabular}{|c|c|c|c|c|c|c|c|c|c|}
\hline \multirow[b]{2}{*}{ Gene } & \multirow[b]{2}{*}{ Unigene } & \multirow[b]{2}{*}{ Description } & \multicolumn{2}{|c|}{ Psoriasin } & \multicolumn{2}{|c|}{ Calgranulin- $A$} & \multicolumn{2}{|c|}{ Calgranulin-B } & \multirow[b]{2}{*}{$\mathrm{N}$} \\
\hline & & & $\begin{array}{l}\text { Spearman } \\
\text { correlation }\end{array}$ & $\begin{array}{c}\text { Sig. } \\
\text { (2-tailed) }\end{array}$ & $\begin{array}{l}\text { Spearman } \\
\text { correlation }\end{array}$ & $\begin{array}{c}\text { Sig. } \\
\text { (2-tailed) }\end{array}$ & $\begin{array}{l}\text { Spearman } \\
\text { correlation }\end{array}$ & $\begin{array}{c}\text { Sig. } \\
\text { (2-tailed) }\end{array}$ & \\
\hline CDH2 & Hs.464829 & Cadherin 2 & ${ }^{*} 0,610$ & 0,021 & 0,232 & 0,425 & 0,448 & 0,108 & 14 \\
\hline CDH3 & Hs.76206 & Cadherin 3 & *- 0,572 & 0,033 & $-0,226$ & 0,438 & 0,179 & 0,541 & 14 \\
\hline CDH6 & Hs. 171054 & Cadherin 6 & $-0,507$ & 0,064 & $-0,522$ & 0,056 & $* *-0,682$ & 0,007 & 14 \\
\hline IFITM1 & Hs.458414 & Interferon induced transmembrane protein & $-0,276$ & 0,340 & $-0,400$ & 0,156 & *-0,536 & 0,048 & 14 \\
\hline ITGA5 & Hs.505654 & Integrin alpha 5 & $-0,056$ & 0,849 & $-0,354$ & 0,215 & ${ }^{* *}-0,825$ & 0,000 & 14 \\
\hline ITGA6 & Hs.133397 & Integrin alpha 6 & $* *-0,663$ & 0,010 & $-0,150$ & 0,610 & 0,023 & 0,938 & 14 \\
\hline ITGAV & Hs.436873 & Integrin alpha $\mathrm{V}$ & 0,193 & 0,509 & ${ }^{*} 0,553$ & 0,040 & 0,521 & 0,056 & 14 \\
\hline ITGB4 & Hs. 632226 & Integrin beta 4 & ${ }^{*} 0,614$ & 0,020 & 0,450 & 0,106 & 0,457 & 0,100 & 14 \\
\hline MUC1 & Hs.89603 & Mucin1 & ${ }^{*} 0,613$ & 0,020 & ${ }^{*} 0,595$ & 0,025 & ${ }^{*} 0,660$ & 0,010 & 14 \\
\hline
\end{tabular}

$\mathrm{N}$, number of libraries

${ }^{*}$ Correlation is significant at the 0,05 level

${ }^{\star *}$ Correlation is significant at the 0,01 level 


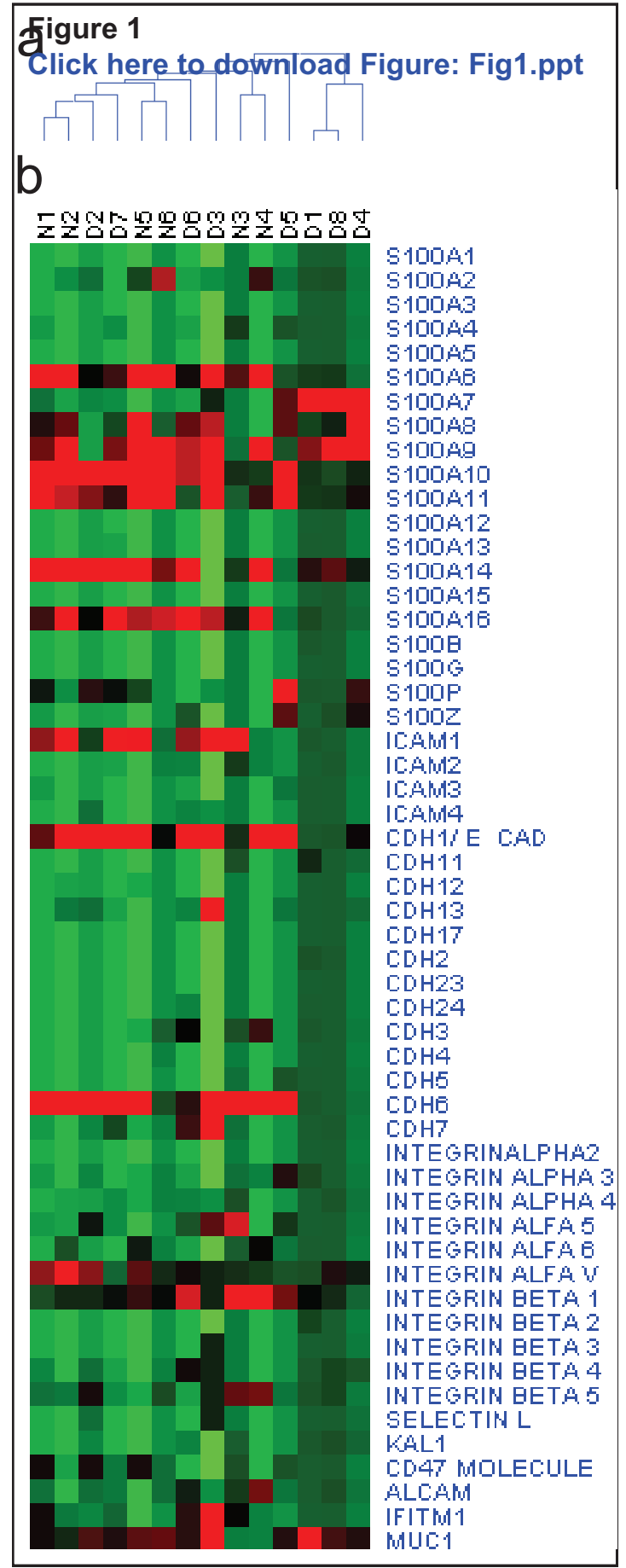




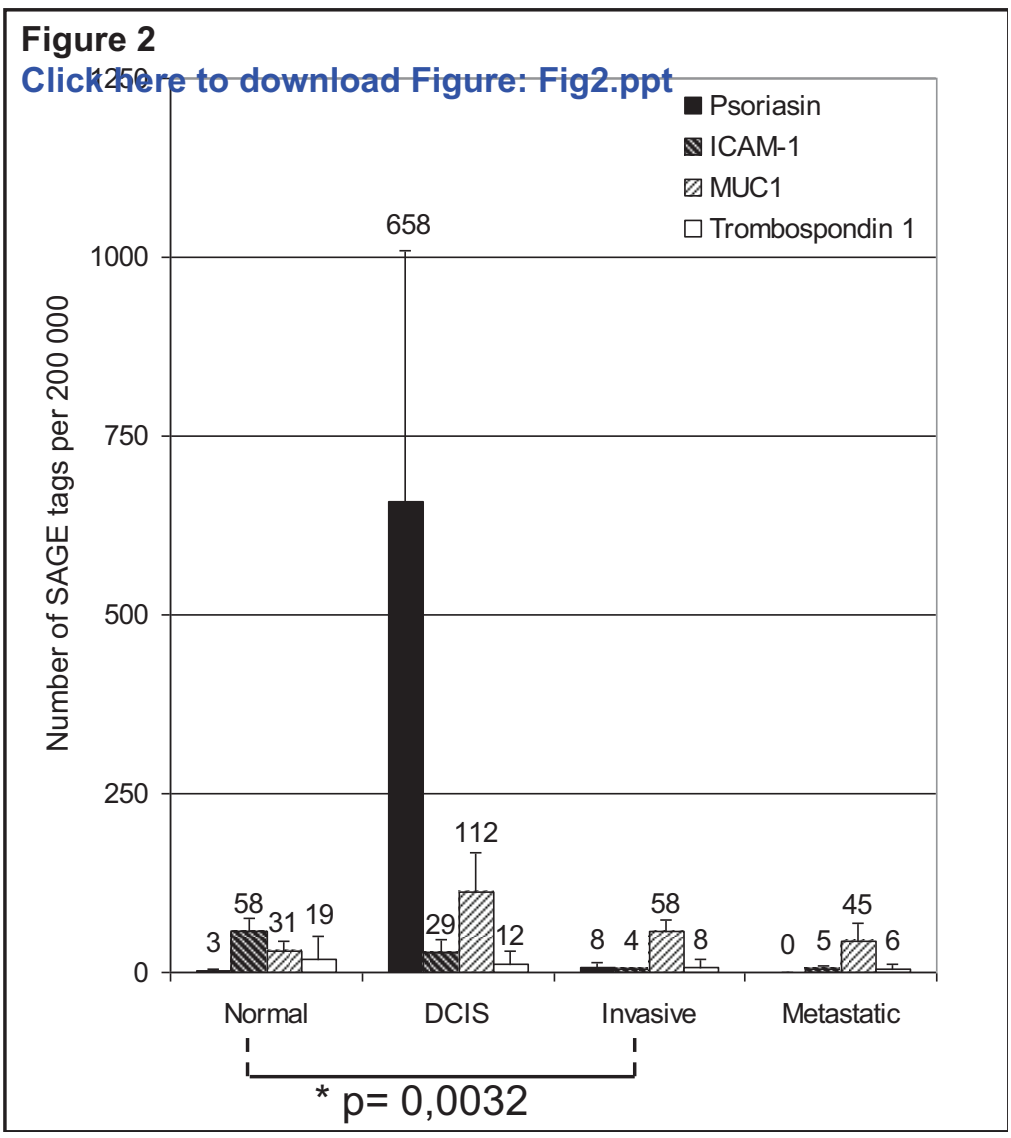




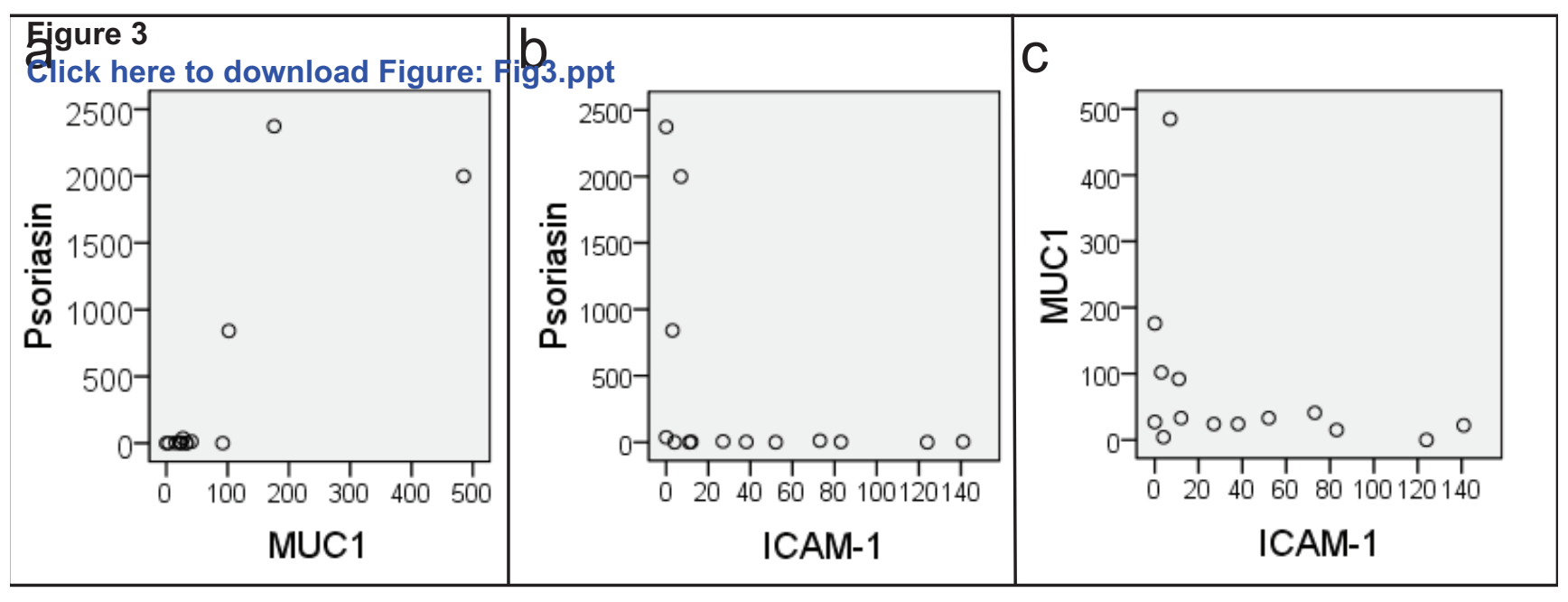




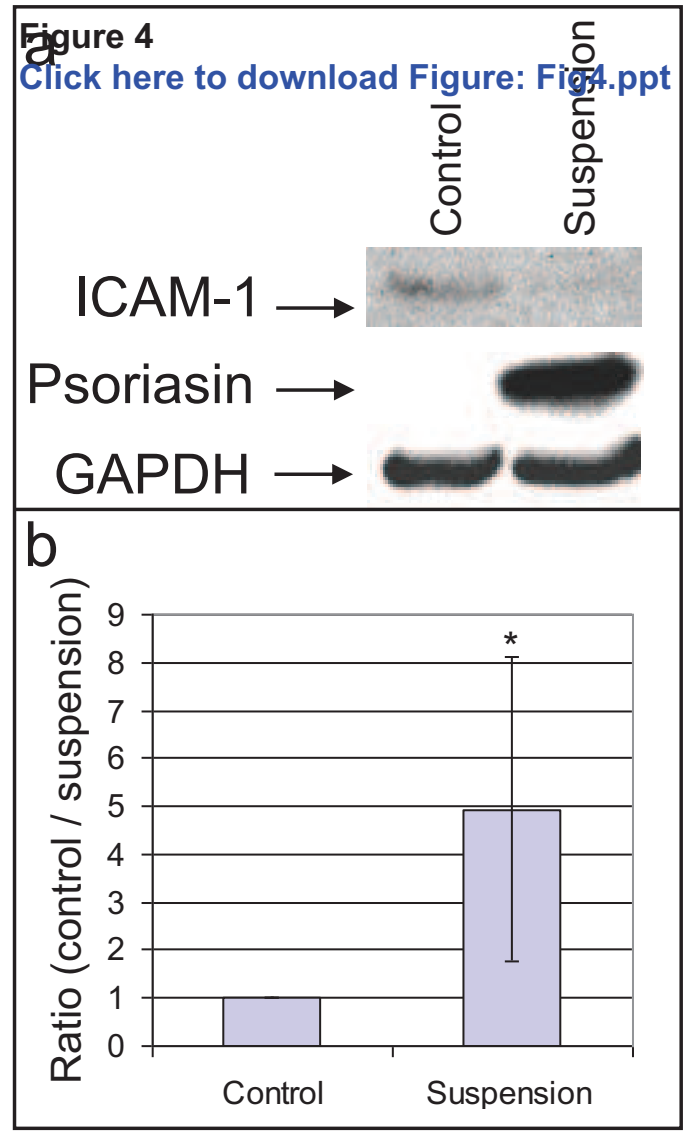




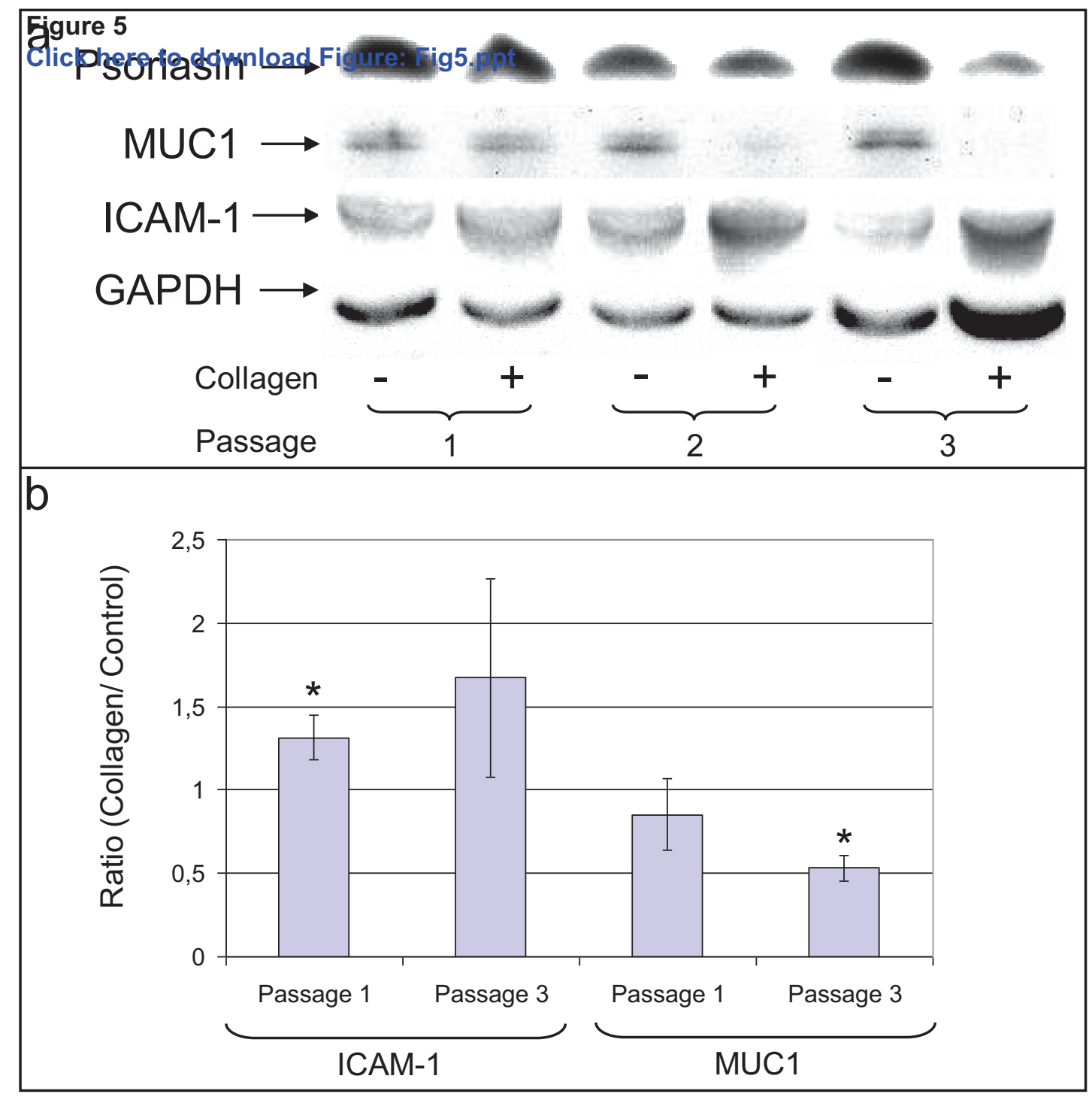




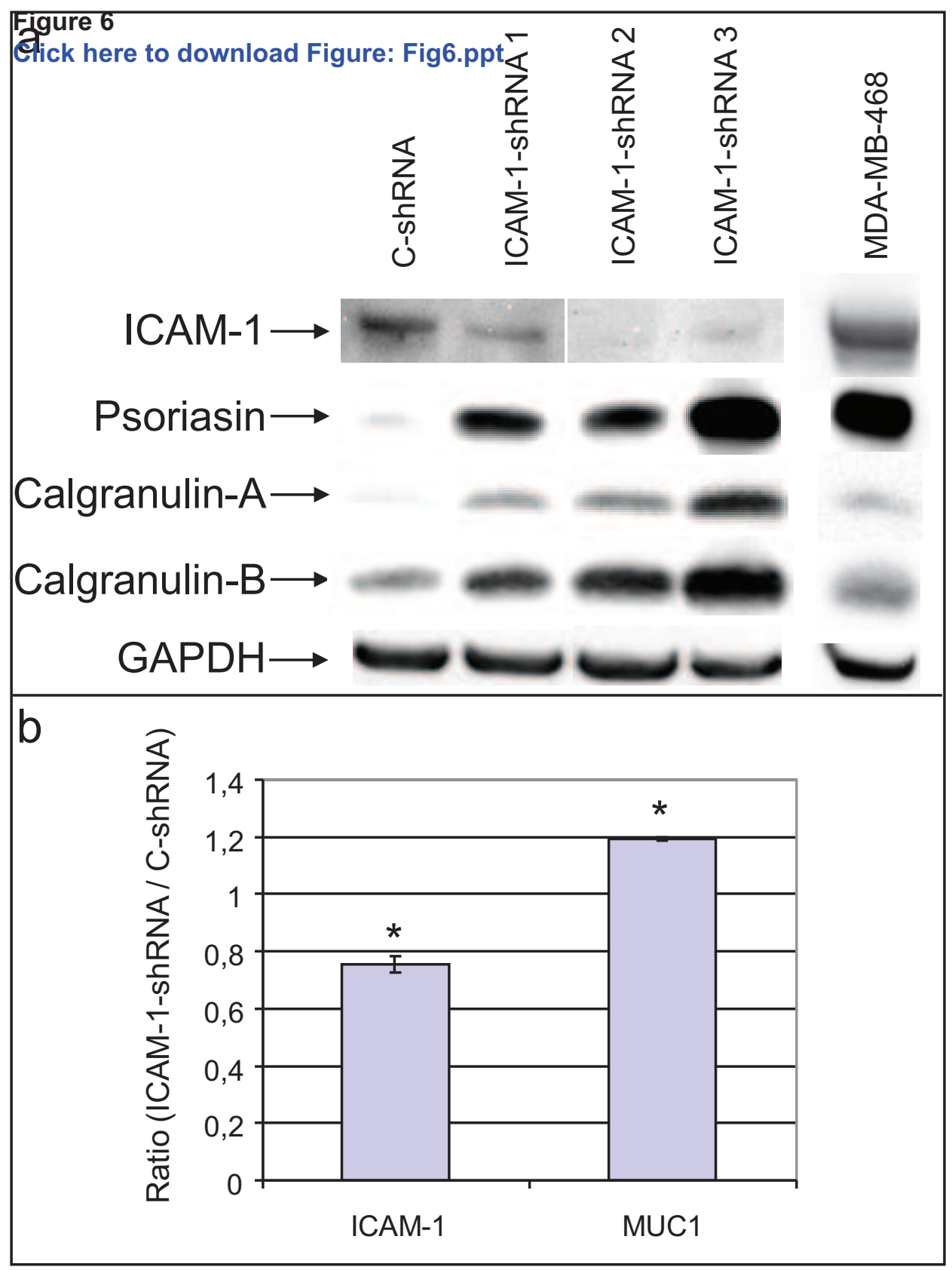




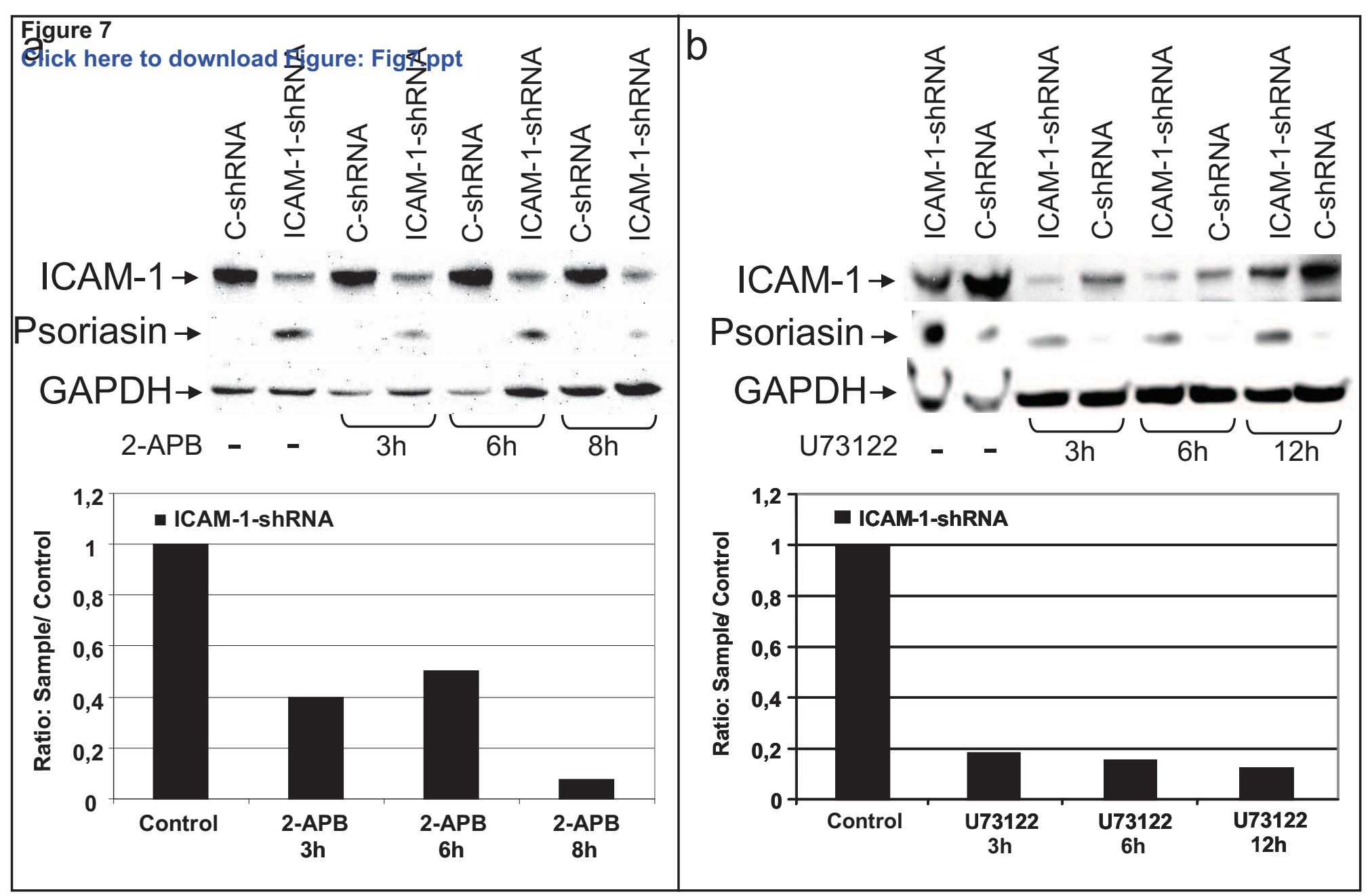




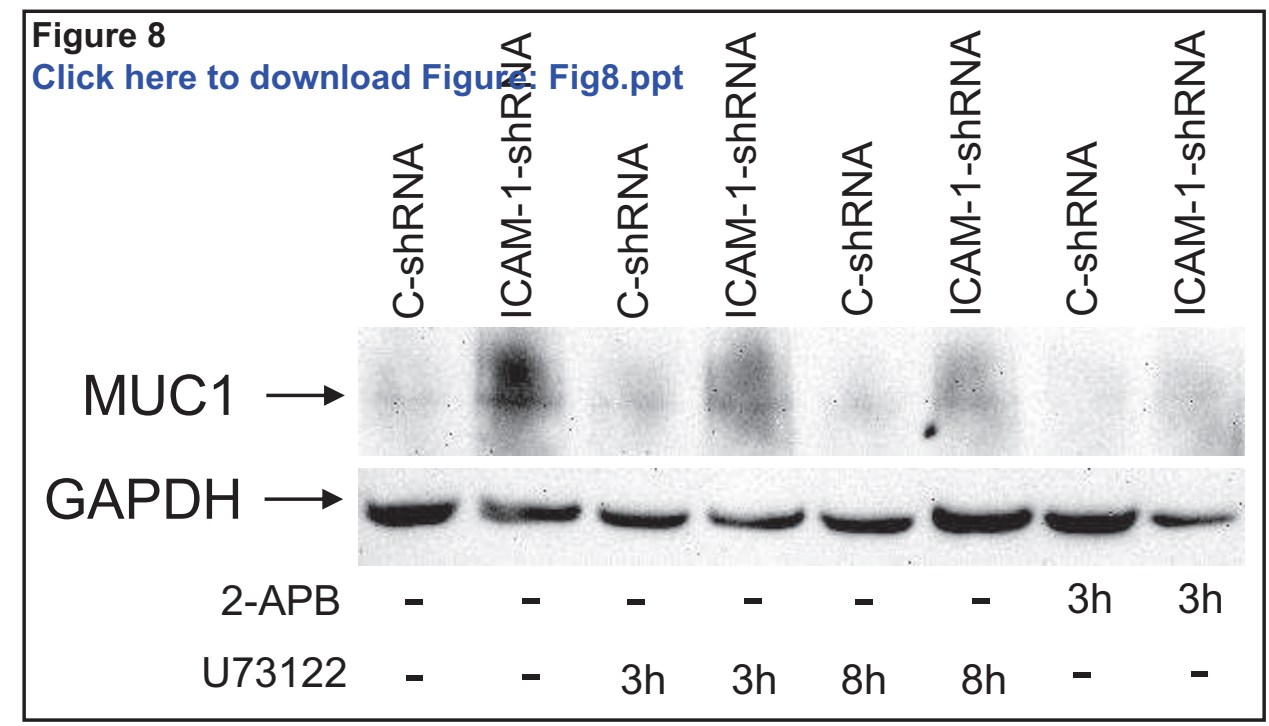




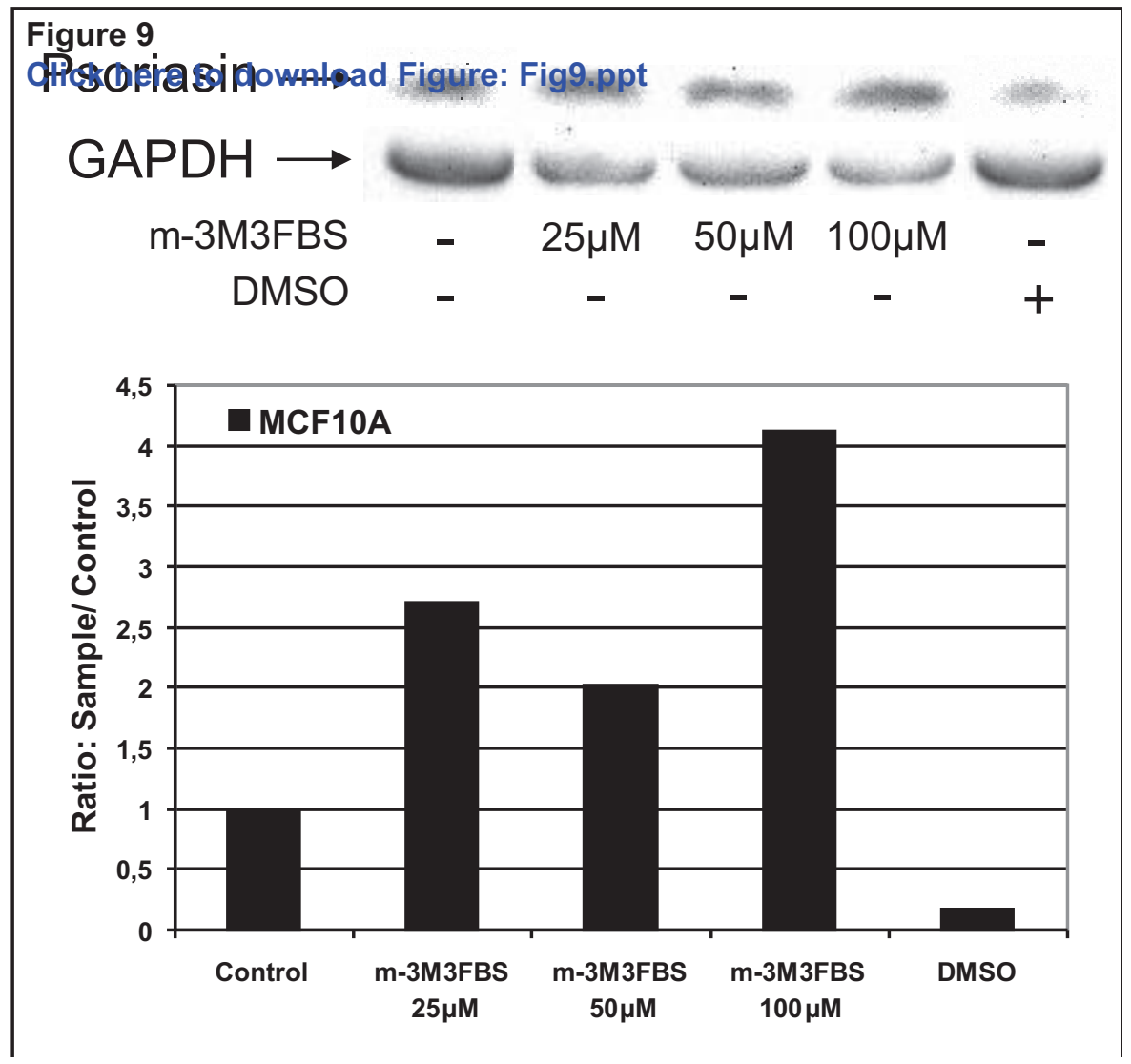


Egure 10

Click here to download Figure: Fig10.ppt

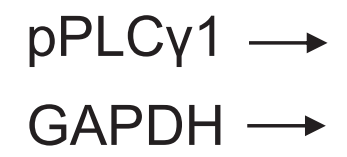

$\mathrm{m}-3 \mathrm{M} 3 \mathrm{FBS}$

DMSO

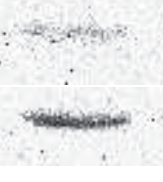

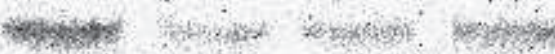

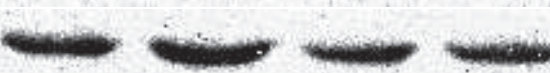

$\begin{array}{llll}5^{\prime} & 15^{\prime} & 30^{\circ} & -\end{array}$

b
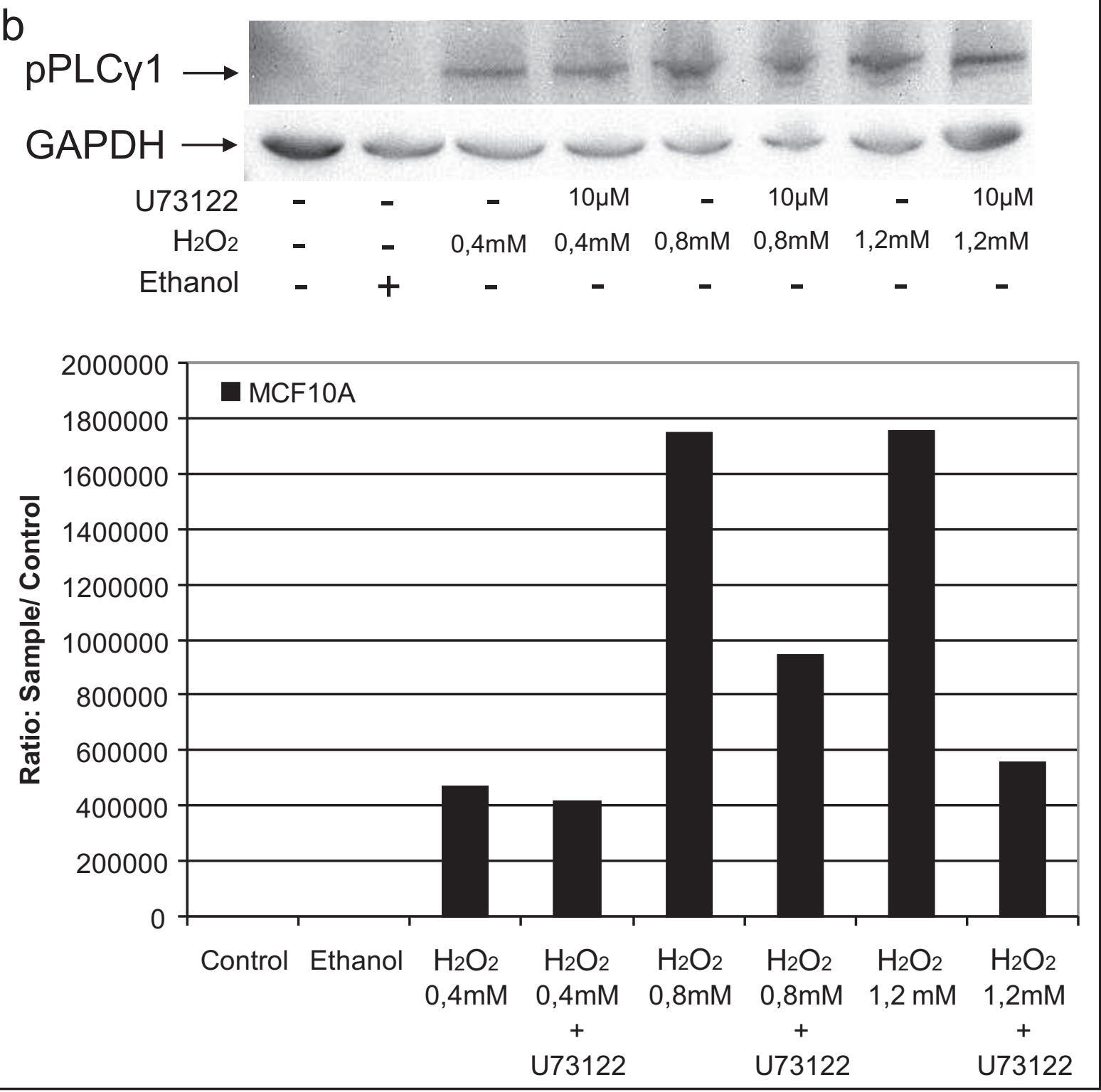


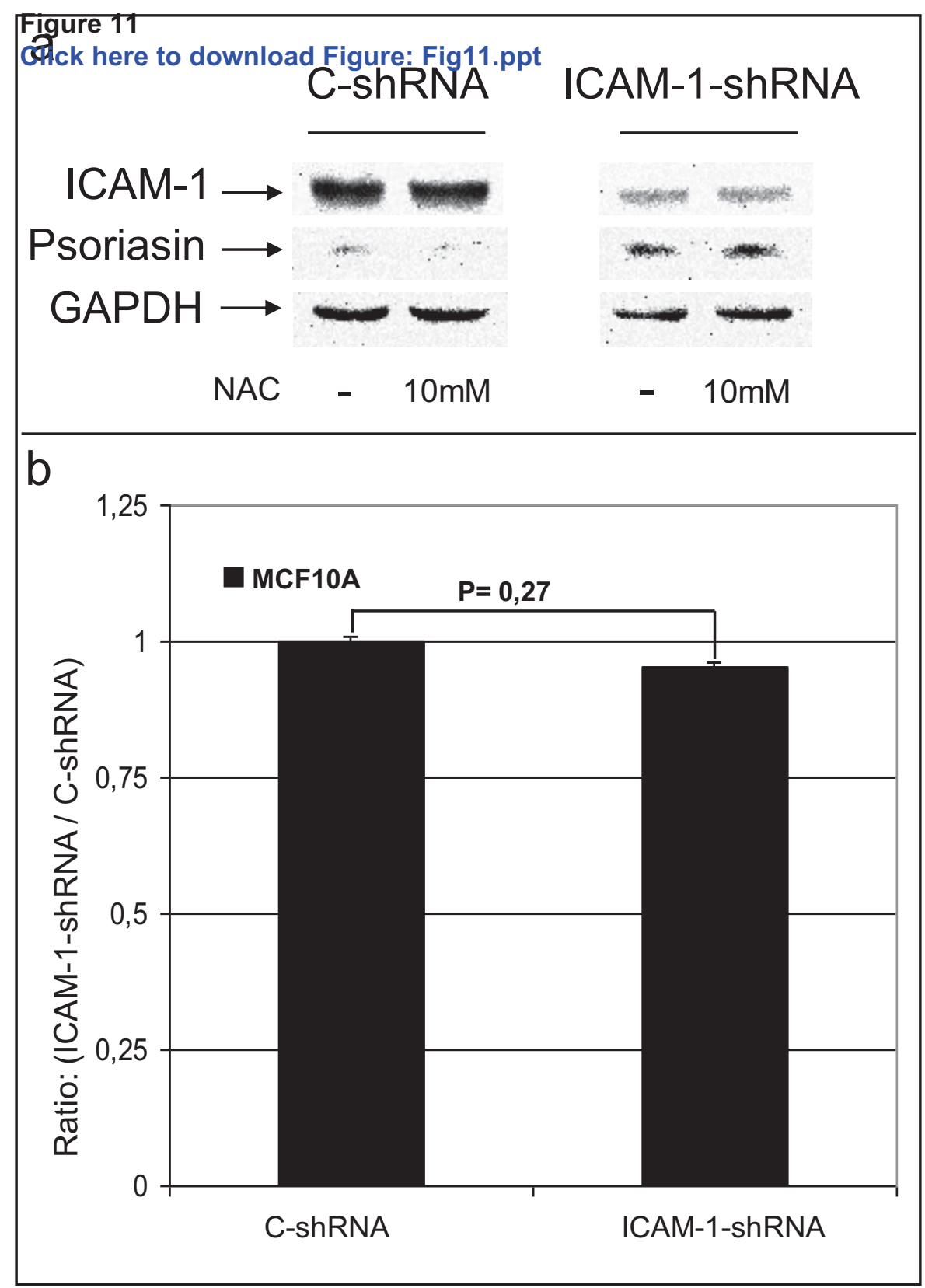




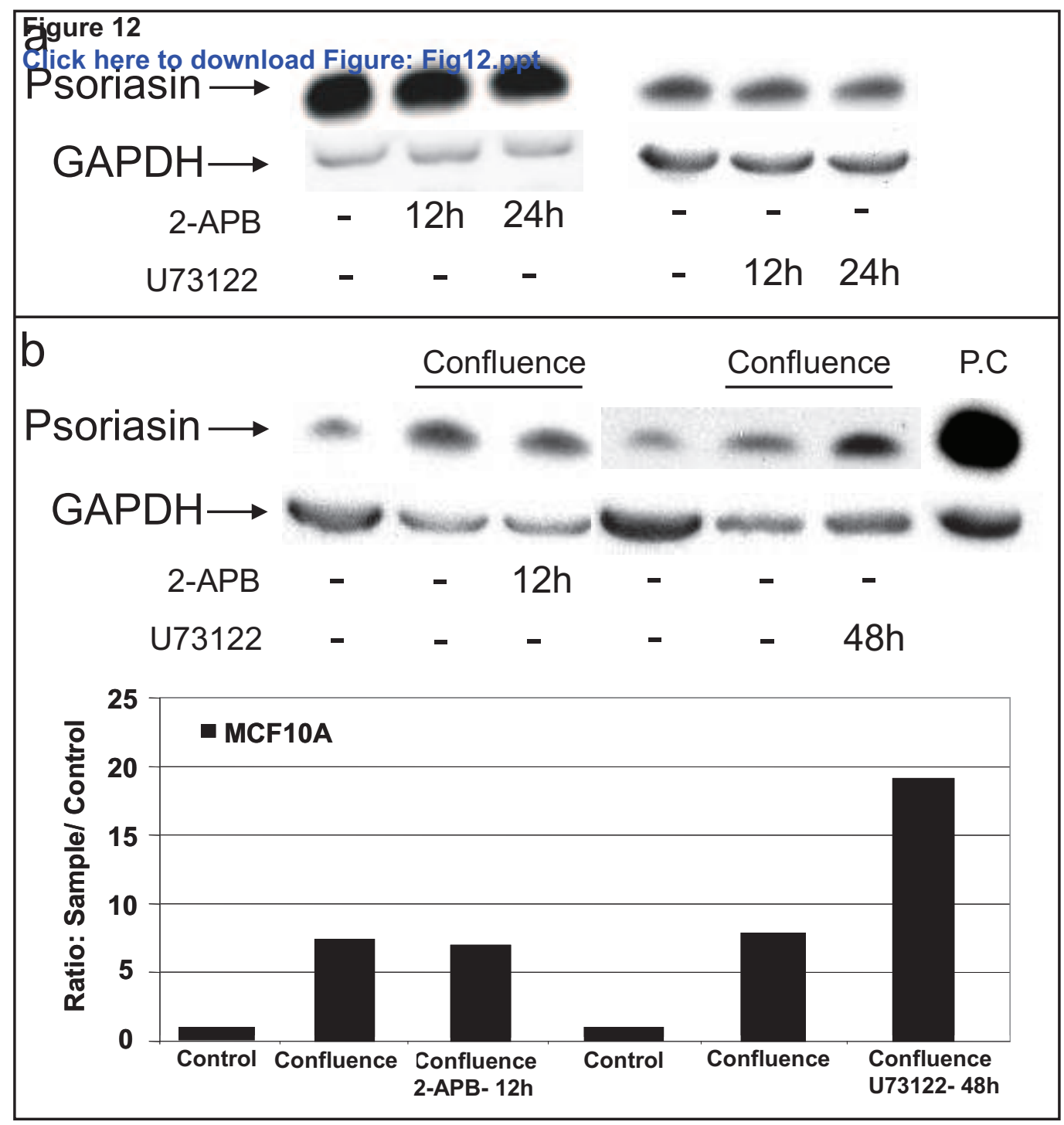




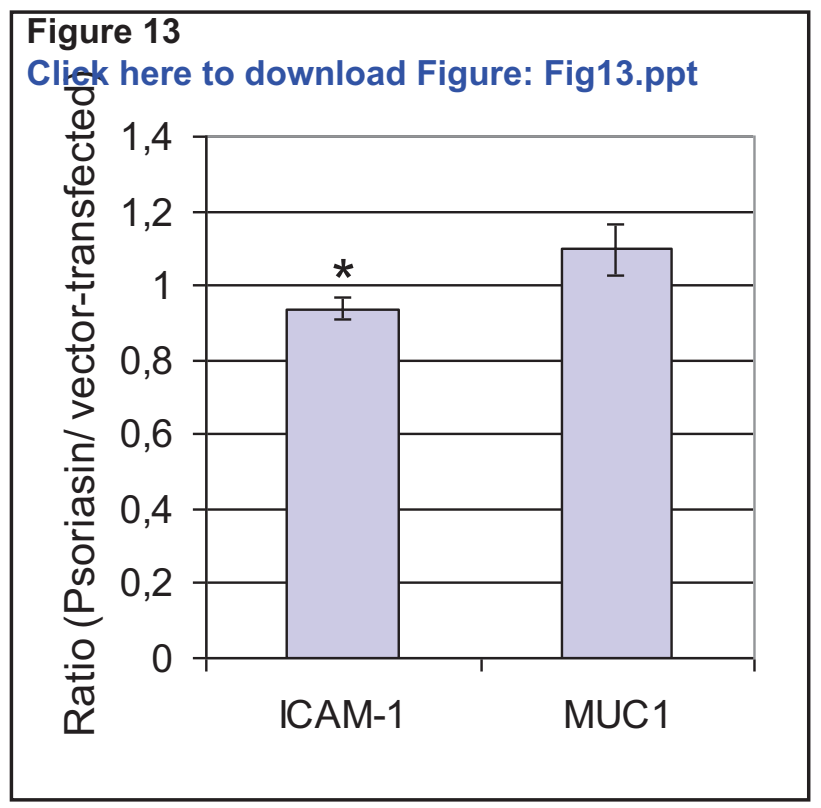

